\title{
PERCEPÇÕES, IMAGENS, PALAVRAS: Os significados, a formação e o desenvolvimento humano
}

\author{
Perceptions, images, words: The significations, the human \\ graduation and development
}

\begin{abstract}
Neli Klix Freitas
DocenteEfetivadaUniversidadedo Estado deSantaCatarina, D outoraem Psicologia, Florianópolis, SC - Brasil,e-mail:neliklix@ terracom.br
\end{abstract}

\section{Resumo}

A proposta deste artigo é a de apresentar questões teórico-conceituais e reflexões sobre o papel e a importância dos significados na formação e no desenvolvimento humano. As percepções e imagens asso ciadas às palavras, relacionadas com tempos iniciais da vida são significativas nas escolhas e nas trajetórias humanas. Referimo-nos também, aos professores. A tividades de ensino envolvem uma complexa trama conceitual que integra teoria, pesquisa, formação pessoal e profissional. Ensino e formação contemplam a interdisciplinaridade, sem perder de vista as especificidades, em cada área do conhecimento. Ao longo dos dois últimos anos foram por nós desenvolvidos estudos e atividades de pesquisa sobre formação humana em Florianópolis, Santa Catarina, particularizando o professor e os significados em sua trajetória profissional, permeada por continuidades e rupturas.

Palavras-chave: Formação. D esenvolvimento humano. Imagens. Palavras. Significados.

\begin{abstract}
The purpose of this article is to present theoretical questions and reflections about the role of significations in human graduation and development. Perceptions and images associated with words, are important in human professional options and experiences. The teaching activities involves many topics: theory, research, human and professional graduation. Teaching and graduation reinforcing the idea about the importance of interdisciplinarity and specific questions in different areas of knowledge. During two years we were develop studies and research in Florianópolis, Santa Catarina, focuses the teacher's ways, formal aspects of graduation, ideas and significations in professional ways.
\end{abstract}

Keywords: Graduation. Human development. Images. Words. Significations. 


\section{INTRODUÇÃO}

Vínculos iniciais da vida asseguram uma base segura para lidar com o cotidiano, fazer escolhas, inclusive no âmbito profissional. Trajetórias de vida e trajetórias profissionais inserem-se na gama de projetos humanos, que possibilita sentido à existência. Identificações com figuras de vínculo também permeiam motivações para as escolhas profissionais e, nesse âmbito, 0 imaginário desempenha um importante papel, asso ciando sonhos, projetos, vivências, desejos com a realidade, com as escolhas do cotidiano. Significa conhecer a familiaridade das ações e de sua prática, ações essas que vão dando forma à construção do real. As imagens formadoras se atualizam em suas inserções no dia-a-dia de cada um. $\mathrm{O}$ confronto com as vicissitudes da vida exige a elaboração do sofrimento gerado pela falta, pelas perdas, que podem ser diversas: desde a mudança de cidade, até aperdapormortedeumapessoaamada. $\mathrm{O}$ confronto com a dor, sem qualquer negação, favorece a elaboração. A partir daí é possível ressignificar práticas profissionais criativas e os elos com a existência. Ao longo do ciclo de vida, seres humanos sofrem impactos do interjogo existente entre identificação e desidentificação.

Muitas vezes, instaura-se um certo distanciamento que, depois de elaborado, passa a ser devolvido pelo próprio sujeito a si mesmo. Momentos atuais são também momentos de incerteza e, por si mesmos representam desafios importantes, que podem levar a fraturas na identidade e nos processos de identificação. Um tempo nem grandioso, nem épico, antes prosaico, porém fecundo. Voltando o olhar para o professor, pode-se referir que existe um fio condutor em sua identidade e trajetória, permeada por múltiplas imagens, percepções e sensibilidades, que estão envoltos nas tramas da memória e da história de cada um. Muitas vezes, as vicissitudes se apresentam como momentos de incerteza, de fragmentação desse fio condutor que articulaidentidade, memória e projeto de vida. Podem quebrar-se imagens de si, estruturas subjetivas, eo professor pode permanecer preso a uma formação anterior, que já não coincide sequer com suas expectativas pessoais. Crises aparecem, até mesmo pelas mudanças aceleradas, que reclamam por um olhar mais atento às manifestações da memória diante das vicissitudes da vida. As crises vitais e as tramas sociais representam registros diacrônicos na história de vidadas pessoas. D iantedessas questões, aformação reveste-se de importância, ressignificando 0 caminho, a realidade e a própria vida, permeada por escolhas e confrontos permanentes.

Uma dissociação entre formação profissional e humana cinde o sujeito de seu próprio tempo efragmentao conhecimento. Tanto aformação permanente, a formação profissional, quanto a formação humana passam por continuidades e rupturas, mas integram, configuram e reconfiguram projetos de vida. E necessário voltar o olhar para a formação do professor que, em muitos casos não coincide com as demandas atuais. Encontrar os vínculos entre tempo e ensinar, tempo e aprender resulta familiar aos coletivos docentes Encontrar os mesmos vínculos entre tempo e formação do ser humano resulta distante. A dificuldade está na falta de familiaridade com a formação. Será, então, que a formação é estranha à docência? Por que será, se educação e formação sempre caminharam tão próximas? Sabe-se bastante sobre o que, e sobre como ensinar, mas sabe-se pouco sobre a formação humana: professores e alunos como sujeitos totais, éticos, culturais, estéticos, afetivos. 0 movimento de realização permite 0 aparecimento de fenômenos educativos, no sentido estrito do termo, que os vincula aos significados. O fundamento dos fenômenos e seus desdobramentos se manifestam numa temporalidade, numa especialidade, existencialmente, e não apenas como resultado de recursos metodológicos. A essência daquilo que existe está no como este isto se manifesta, e existe coincidência entre 0 ser, 0 isto, a aparência, a manifestação da realidade. Estes aspectos estão implícitos também no processo de atribuição de significados às vivências e experiências. É um movimento dinâmico, como a própria vida.

As questões teórico-conceituais e as reflexões deste texto partiram dos dados analisados de duas pesquisas por nós desenvolvidas, inseridas no tema da formação de professores de diferentes áreas, particularizando o professor de Artes Visuais, mas vinculados ao ensino. 0 foco recai sobre a associação entre imagens e palavras na atribuição de significados às vivências e experiências ao longo do desenvolvimento humano. Nesta perspectiva diferentes aspectos do desenvolvimento humano e da formação são apresentados e teoricamente fundamentados. Referem questionamentos dos professores diante das vicissitudes da vida, da 
trajetória profissional, inserindo reflexões sobre 0 tema, em uma abordagem que contempla uma complexa trama conceitual.

\section{Desenvolvimento do tema: Q uestões teórico-conceituais e reflexões}

Defrontamo-nos na atualidade com uma encruzilhada histórica nas áreas da psicologia, da educação, da arte, do conhecimento. 0 processo tecnológico ascende sem parar, e assistimos maravilhados às conquistas do mundo virtual. A era dasfibrasóticas, dainteligênciaartificial, do computador neural, das redes e da robótica pode melhorar a vida dos seres humanos e democratizar a produção do conhecimento. Entretanto, vive-se também 0 paradoxo: a miséria absoluta cresce assustadoramente.

Alguns cientistas alertam para a necessidade dabuscade significado social da ciência, e lutam por uma ciência com rosto humano. Esses estudiosos são justamente aqueles que estão comprometidos com uma ciência holística ou, dito de outro modo, com uma poética científica em diálogo com a natureza e com os seres humanos. Papert (1993), teórico dainteligênciaartificial coloca no âmago da questão uma nova revolução tecnológica, versus uma revolução também nova e genuína no desenvolvimento pessoal. Para o autor, a opção pela tecnologia pura pode ampliar a sede pelo poder, que é destrutiva e destruidora. Aqui, assinala para a necessidade de olhar para uma bifurcação no caminho do conhecimento. $\mathrm{Na}$ realidade, pode-se mudar o rumo da História: escolhe-se a possibilidade de permanecer na doença do sistema, que supervaloriza a tecnologia, com a destruição de significados humanos, ou pode-se avançar rumo ao convívio ético e solidário, no qual a tecnologia une-se aos processos de subjetivação tipicamente humanos.

Nessa direção, os homens devem ser protegidos de si mesmos. Muitas vezes, bloqueiam 0 trabalho intelectual, que poderia resultar em esquemas justificadores das ações disfuncionais. 0 sujeito deixa então, de perceber uma parte da realidade exterior, e uma parte de seu universo psíquico, como se proibisse a si mesmo de pensar. O espaço de trabalho, assim como o cotidiano transformam-se em um fazer destituído de significados, resultando daí um sujeito cindido de seu mundo, de si e de sua essência (Wallon, 1979).
Um ambiente pobre em estímulos simbólicos não oferece condições adequadas para a construção do conhecimento. Alguns professores ignoram como uma pessoa aprende, como interage os complexos processos psicológicos, neurológicos, cognitivos, imaginativos e sócio-interativos. Segundo Rego (2002) esses professores bloqueiam 0 próprio acesso e 0 de seus alunos a qualquer possibilidade de aprendizagem significativa.

Segundo Wallon (1979), existe, então, um descompasso entre saber e conhecimento. 0 saber possui uma dimensão que reporta ao significado das vivências, à memória tida como tempos vividos e ao imaginário, enquanto o conhecimento envolve a consciência. Quando o conhecimento não coincide com o saber do sujeito que aprende, surge uma fratura importante, que é patogênica e impede 0 desenvolvimento. O Construtivismo e o SócioInteracionismo em Psicologia e em Educação, segundo Piaget, Wallon e Vygotsky apoiam-se na concepção de que, para que haja conhecimento deve existir uma ação sobre a realidade e uma ressignificação simbólica.

Em seus estudos, Vygotsky (2001) buscou respostas a uma série complexa de questõ es inserida no desenvolvimento de cada indivíduo. A primeira questão tem como foco a compreensão da relação entre os seres humanos e o meio. A segunda questão busca a identificação de novas formas de atividade, inserindo 0 trabalho na dinâmica do desenvolvimento humano como meio fundamental derelacionamento com a naturezae consigo mesmo. A terceira questão relaciona-se com a análise das relações entre 0 uso de instrumentos e 0 desenvolvimento da linguagem, que possibilita a atribuição de significados e a construção de sentidos para o que se vivencia e se faz.

Vygotsky $(1984,1986,1987)$ dedicou-se ao estudo das funções psicológicas superiores tipicamente humanas, como a imaginação, a capacidade de planejamento, a memória, a construção de representações mentais, que incluem mecanismos interacionais, com possibilidade de manter certa independência diante das características e pressões do momento, do tempo e espaço presentes. Trata-se de funções que não são inatas, mas que se originam nas relações entre indivíduos humanos, e desenvolvem-se ao longo do processo de internalização de formas culturais de comportamento. A partir daí pode-se compreender a existência de uma interação dialética do homem 
com seu meio sócio-cultural. Ao mesmo tempo em que 0 ser humano transforma o meio para atender suasnecessidades básicas, transforma-seasimesmo. Há um espaço dinâmico e contínuo de construção, desconstrução e reconstrução de imagens e significados ao longo do desenvolvimento humano. O bserva-se a integração de aspectos biológicos e sociais do indivíduo nesse processo.

Para Luria (1992) as funções psicológicas superiores do ser humano surgem da interação dos fatores biológicos, que são parte da constituição física do $\mathrm{H}$ omo Sapiens com os fatores culturais, que evoluíram através das dezenas de milhares de anos da história humana.

As funções psicológicas superiores originam-se nas relações do indivíduo e seu contexto sócio-cultural. Isto é, o desenvolvimento humano não é dado a priori, não éimutável, não há passividade, nem independência do desenvolvimento histórico e das formas sociais da vida humana. Rego (2002) refere-seàculturacomo parteconstitutivadanatureza humana, já que sua característica psicológica se dá através da internalização dos modos historicamente determinados e culturalmente organizados de operar com informações.

Pode-se apreender que há imagens iniciais decorrentes de momentos mais primitivos da vida, mas que não são estáticas. Ao abordar a consciência humana há necessidade de estudar mudanças que ocorrem no desenvolvimento mental a partir do contexto social, que é mutável como a própria vida. As imagens iniciais, denominadas de formadoras não são apenas sensoriais, uma vez que o homem não vive somente no mundo das impressões imediatas, mas também no universo dos conceitos abstratos e dos significados. D ispõe de conhecimentos racionais, possui a capacidade de adentrar na essência das coisas. Durante o desenvolvimento existe um salto significativo no processo do conhecimento, desde 0 sensorial até 0 racional.

Na realidade, o faber está sempre em nós. O sapiens entra na esfera da poiética, como noesis poieseôs. ${ }^{1}$ Esse pensamento corrosivo evoca lembranças de acasos interiores aos contornos da conduta e, numa meditação mimética, retoma a formação humana inicial, possibilitando múltiplas revelações.
Pode-se efetivar uma analogia da formação humana com a arte: ambas não cessam nunca de repetir tentativas de liberação e que, longe de se limitar à invenção de formas estéticas, e de visar o belo desobstruem os conteúdos afetivo-escato-mortuários, dos quais a pessoa não se purifica jamais inteiramente. As palavras, ações e lembranças possuem significados que são, ao mesmo tempo, evidentes e enigmáticos. A memória como tempos vividos relaciona-se com a consciência (memorial), nas bordas do passado. Ela reviveeinventalembranças. Atravésdosmitospessoais, muitas vezes o dasein se faz história, afim de figurar sob o olhar do outro. 0 outro está em nós, uma vez que a identidade se edifica e se configura em interação social. Pela história, o essencial abre um caminho, e a noite do pensamento tenta fazer memória. Para Passeron (1997) há lembranças, há imagens iniciais e formadoras, nem sempre felizes, mas marcantes, que seconstituem como essenciaisnadinâmicadaformação humana. Entretanto, muitas delas desaparecem, e outras permanecem vívidas na memória, podendo ser resgatadas nas vivências do cotidiano.

O ssignificados emergem esão explicitados pela palavra, encadeando um pensamento através do outro em experiências sensíveis, nas quais há uma estreita associação entre memória, percepção e sensibilidade. Refletir sobre a formação humana, sobre os significados, sobre trajetórias de vida significa admitir que, para cada ser humano existe um percurso singular. Pelas diferenças e nas diferenças deflagra-se tudo aquilo que é particular, que se revela na expressão de linguagens também pertinentes a cada sujeito: verbal, visual, corporal, musical, dentre outras.

Pasolini (1990), cineasta, artesão da imagem e, por isso mesmo capaz de perceber 0 poder sutil da lente de uma câmera, ao efetuar um desvelamento da face oculta da realidade, oferece uma análise sobre o mundo dos objetos criados pelo homem no mundo em suas diferentes profissões e trajetórias. Suas ideias coincidem com as de Benjamin (1987) quando refere que a linguagem desempenha um papel primordial. É possível ler e decifrar nas coisas, nos objetos, paisagens, gestos, atos, palavras códigos da cultura. A questão reside em fazer falar esse mundo dos objetos que age so bre as pessoas, revelando um potencial de sentido, que

\footnotetext{
$\overline{1}$ Noesis poiseôs, do grego. Significa pensamento de criação. (Passeron, 1997).
} 
se desvela pela e na linguagem. A leitura da realidade ocorre pelaviada palavra, assim como os significados das vivências são atribuídos também pela palavra. $\mathrm{Ou}$, dito de outro modo, de imagens mais palavras.

Pasolini (1990, p. 63), escreve que "as primeiras lembranças da vida são visuais. A vida, na lembrança, torna-se um filme mudo. Todos nós temos na mente a imagem que é a primeira, ou uma das primeiras danossavida. Pelapalavra, o significado da imagem pode ser revelado, desvelado."

A realidade emerge pela via da linguagem, e não pode ser vivida senão nessa experiência existencial direta, concreta, dramática e corpórea. Pasolini (1990, p. 71) prossegue dizendo que "a primeiraimagem da minhavidaéuma cortina, branca, transparente, que pende de uma janela que dá para um beco escuro e triste. Naquela cortina se resume e toma corpo o espírito da casa em que nasci."

$\mathrm{O}$ autor explica ainda que a educação que uma criança recebe dos objetos, das coisas, da realidade física, dos fenômenos materiais de sua condição social torna-o corporalmente aquilo que é e será por toda a vida. Educa-se o corpo, como forma de expressão do espírito.

A proposta que emerge de diferentes ideias de Pasolini (1990) e de Benjamin (1987) é a da existência de uma linguagem pedagógica das coisas que permite resgatar a compreensão crítica da realidade, e recuperar o olhar sensível sobre o mundo, procurando lugares de refúgio do sagrado, ou seja, do significado de um rosto, de um objeto, de uma paisagem; ir em busca do invisível que se esconde e se presentifica na linguagem-imagem das coisas.

Para que isso se configure como realidade é necessário dirigir um olhar atento e respeitoso para as coisas do mundo, que permite desenvolver uma nova ética do olhar. A linguagem pedagógica das coisas ensina que existe um modo novo de acercar-nos da verdade que se refugia nos objetos, nas paisagens, nos rostos das pessoas que povoam nossas lembranças. Trata-se de um olhar ético, que despertapelalinguagem, que possibilitaaemergência de valores de expressão, de recriação de emoções já vividas, implícitas na construção do conhecimento.

Perguntas e respostas distintas existem porque há lembranças, que podem ser felizes, mas que são também vinculadas a problemas, trazendo conflitos. Estes relacionam-se com a complexa dinâmica existente entre realidade interna e externa. Seres humanos são por sua própria essência, questionadores. Inquietos, alguns mais do que outros buscam vetores de sentido para suas inquietações, diante de um mundo permeado por hipóteses prontas para se tornarem reais, para atualizar-se frente às demandas do cotidiano. A busca do novo pelo conhecimento possibilita atualizações constantes. Estas podem responder a muitas das demandas internaseexternasdos sujeitos. Entretanto, hásempre uma busca por algo muito mais amplo do que a informação. Os vínculos que caracterizam a espécie humana necessitam de reabastecimento afetivo, para que as inquietações dominantes não aniquilem investimentos criativos. A civilização necessita desses investimentosparanão sucumbir diantedo sofrimento que emana das vicissitudes da vida, como a miséria social, a violência, o desemprego, a fome, a solidão das grandes metrópoles. Segundo Freitas (2005), estados de letargia podem instalar-se quando não se encontram nexos entre as demandas do cotidiano e as imagens mais remotas da vida, inseridas na história e na memória de cada um.

Tratam-se de imagens formadoras. Essas imagens convocam para tudo quanto é carregado de presença, como também para o que é carregado de ausência, desgastando cargas existenciais e espirituais. Caminhadas humanas são especulativas, impregnadas pelo desejo de ver, de ter, de ser, que impulsionam para a busca por lugares seguros, imaginários, utópicos ou até mesmo, idealizados. Lugares para frente, lugares para mais atrás, antes e atrás das origens. Lugares humanos.

Para Vygotsky (1987), as primeiras impressões são visuais, associadas às imagens. São sensoriais: táteis, olfativas, gustativas, sonoras. Mas, são significativas, uma vez que estão inseridas na história de vida de cada um. Assim, na história de cada sujeito humano os pensamentos percorrem vias deacesso apensamentosaindanão pensados, envoltos pelas aspirações e vinculados com o desejo: desejo de ser, de realizar, de conviver. É a constante busca humana pela realização, pela felicidade, que envolve processos psicológicos superiores, tais como a percepção, a imaginação, as representações mentais.

As inquietações humanas, segundo Freitas (2005), conduzem a convocações equestionamentos. São estados em suspensão, estados de ser e de estar. Podem fazer prevalecer uma potência poética em si mesma, ressignificando a própria existência, tanto pela manutenção dos vínculos com as imagens formadoras, como pela ruptura com as mesmas, ou mesmo pela atribuição de novos significados. Tratase de uma necessidade constante de redimen- 
sionamento, que desperta energias embutidas, agindo sobre as estruturas primitivas da existência humana, como matéria desejando tornar-se linguagem.

Segundo Vygotsky (1987), existe um percurso singular para cada um e para cada contingênciahumana. Todas as formulações humanas são feitas a partir do convívio com o meio, motivadas pelas interações sociais. Mas, as trajetórias são particulares, uma vez que cada um apropria-se do meio, da sociedade e da cultura de acordo com suas sensações, percepções, imaginações. As representações mentais, funções psicológicas tipicamente humanas permitem a permanência dos objetos e das vivências mesmo diante de sua ausência. Mas, até por serem humanas, são próprias de cada sujeito, e não há representações mentais idênticas. É interessante observar que, mesmo nas proposições matemáticas quefocalizam o máximo deobjetividade, o percurso dos pensamentos de vários sujeitos nem sempre trilha os mesmos caminhos. Vasconcellos (2002) refere que é nessas diferenças que se deflagra tudo aquilo que é mais particular, que se revela na expressão de linguagens distintas, pertinentes à singularidade dos sujeitos que, ao questionar e ao responder põem em ação a dinâmica da criação.

Para Enguita (1989), nos atos humanos, nas expectativas, nas realizações e nas frustrações as imagens formadoras ocupam um espaço singular. Há situações ao longo da vida que, em si, nada têm de excepcional, de importante. Mas, relembradas tempos depois, em uma visão retrospectiva revelam ter sido momentos significativos, momentos de insight, de vislumbre de novas possibilidades.

Dialogando com Bakhtin, Benjamin Vygotsky, Paulo Freire, dentre outros estudiosos, é possível chegar ao tema central das reflexões que permeiam as associações entre imagens, linguagem e significados. A linguagem permitea expressão, permite adquirir consciência da realidade e, no campo da expressividade, permite 0 acesso à polissemia de significados, à dialogicidade, que se manifesta e se exprime na constituição da consciência em sua dimensão libertadora. Pela linguagem é possível ter acesso aos significados das imagens que povoam 0 universo cognitivo e afetivo dos seres humanos.

Bakhtin (1976) refere que a linguagem artística é um tipo especial de expressão, que possui características próprias, particulares. A expressão estética, que integra essa forma especial de comunicação é ao mesmo tempo individual e social, pois reflete uma fala interior dos interlocutores, e uma fala exterior, assimilada do contexto sóciocultural e econômico no qual está inserida. Para 0 autor é ingênuo acreditar que se possa assimilar como própria uma fala externa, que seja contrária à fala interior, isto é, que seja contrária a toda a maneira verbal e interior de se ser consciente de si próprio edo mundo. Todo 0 ato conscienteéum ato social e comunicativo. A realização de descobertas, tanto no campo científico, como no âmbito das artes nunca se afigurou aos homens como divertimento ou lazer, mas sim, como resposta a um real desafio. A arte encontra-se intimamente vinculadaaos processos criativos humanos. A prova disso é o fato irrefutável de todas as culturas na história da humanidade, todas elas sem exceção, desde o passado mais remoto até os tempos presentes, terem criado obras de arte, em pintura, escultura, música, dança, poesia, literatura como expressões da essencial realidade de seu viver: uma realidade bem mais ampla do que a utilitarista.

As formas de arte, do mesmo modo que as palavras representam uma via de acesso a esse mundo interior de sentimentos, reflexões e valores de vida, uma maneira singular de expressá-los e comunicá-los aos outros. E sempre, ao longo da história, as pessoas entenderam perfeitamente 0 que lhes foi comunicado através da arte. Segundo Vygotsky (2001) a arte é também uma linguagem, eé de todos os seres humanos. Além da arquitetura do cérebro, ou dos circuitos cerebrais, ou ainda da bioquímica do metabolismo, o espaço que circunda os seres humanos contém o conteúdo de experiências humanas. As crianças começam a vida olhando para as coisas e tocando-as; têm que sentar, engatinhar, ficar de pé antes de poder andar: é a ordem natural do desenvolvimento. E, são semprenovos espaços e tempos que descobrem e nos quais se descobrem. 0 autor acrescenta ainda que as imagens iniciais, visuais inicialmente, mesmo que nebulosas mobilizam sentimentos diversos em cada pessoa, que deixam vestígios ao longo da vida. Não há palavras comuns para descrever as mobilizações suscitadas por essas vivências, pois concentram-se em estados puros de sensibilidade. Nos vínculos com questões sensíveis, que reportam às vivências mais primitivas da vida, está em jogo um sentimento do ser da pessoa, um senso de sua própria identidade.

Os significados emergem em contextos constituídos pelas vivências e percepções humanas. Estes, ao se relacionarem entre si e com o conjunto 
que caracteriza a vida de cada um, articulam e dão forma a uma gama de sentimentos e ações que se inserem nas trajetórias de vida. Nunca são fixos, como "isso significa aquilo". O s significados valem naquele contexto, naquela situação. Quando surgem desafios, mudancas no cotidiano, crises e vicissitudes da vida, os significados se alteram, as percepções se modificam e se desconfiguram. Segundo Vygotsky (1986) os significados são explicitados pela palavra, e poroutras formas de comunicação presentesnavida em sociedade. Trata-se da dinâmica da existência humana. Na realidade, perceber significa compreender. Perceber envolve uma participação ativa nos acontecimentos, e refere-se mais a agir do que simplesmente reagir. A palavra dá sentido às percepções.

No ato simultâneo de interpretação e percepção, os contextos projetados pelos seres humanos sobre os eventos, físicos ou psíquicos, sempre reúnem certos dadosjáconhecidos (portanto, reconhecidos), a outros dados inferidos, como sendo prováveis nessas circunstâncias. Os contextos funcionam como uma espécie de moldura delimitadora e seletivaao mesmo tempo. Selecionamse alguns estímulos, avaliam-se, tendo como referência essa moldura imaginária. Os contextos projetados pelos seres humanos mudam de instante para instante, em um gesto ou movimento que se faça, em um piscar de olhos, em um desvio da atenção, ou mesmo em um pensamento que passou voando pelacabeça. Portanto, mudam continuamente osprópriosreferenciais com osquaiscadaser humano identifica as informações e interações. Wallon (1979) escreve que é como se, a cada vez as regras do jogo fossem modificadas. E, no entanto, a maioria dos seres humanos não se perde.

O scontextosprojetados não são arbitrários, nem fantasiosos. São hipóteses, sem dúvida, que devem ser verificadas no contato com a realidade atual. Mas, as expectativas que contém, os pensamentosconscientes eas motivações interligadas a emoções e desejos encontram uma base no acervo de vivências da pessoa. Este acervo começa a ser construído a partir do nascimento, definindo-se ao longo do viver, envolvendo o caráter, as inclinações de cada um, suas potencialidades, seu modo de ser. Dependerá da realidade íntima de cada pessoa a avaliação e o enfoque dos contextos referenciais, e é com base nos mesmos que cada um avalia as informações que recebe. $\mathrm{Na}$ sucessão de imagens que servem de base aos processos de percepção, interpretação e compreensão, cada contexto que for articulado irá influenciar a configuração do seguinte, ao se juntarem dados novos, ou ao se combinar dados de modo diferente. Portanto, sem que o ser humano se dê conta desse processo, cada contexto, cada nova vivência e experiência representam uma etapa na aprendizagem humana, aprendizagem que é também de vida, visto que os resultados são comparados com as expectativas, as quais eventualmente podem ser reajustadas. É assim que se processa 0 crescimento genuinamente humano, no qual as imagens iniciais, formadoras desempenham um papel com caráter de essencialidade. A condição humana sensível, inteligente, consciente representa um potencial que é, simultaneamente inquietante, desafiador e questionador. 0 ser humano necessita criar,até mesmo para desafiar a letargia e crescer, e não patologizar a vida.Essas questões permeiam a existência ao longo da história da humanidade, e não é possível negá-las. São sempre conduzidas novamente, de geração em geração. As respostas evidentemente são sempre diferentes, divergentes. D ependem das visões de mundo, relacionam-se com imagens formadoras, estão vinculadas aos conhecimentos acumulados nas diversas civilizações e culturas, bem como ao modo peculiar de cada um pensar e sentir a vida. Revendo Erikson (1989), pode-se referir que é importante reconhecer que, em cadaserhumano existeumaresposta, um depoimento, uma postura diante do viver. Vindo de épocas mais remotas comunicam-se a cada um constantemente, como que olhando através de frestas, empurrando 0 sujeito a ver as novas dimensões da realidade.

Essa dinâmica complexa e intrincada está presente na trajetória de cada indivíduo: trajetória de vida, trajetória profissional, enfim, trajetória humana. E é exatamente por ser humana que é vinculada à vida. A história de cada um, do nascimento até o final da existência, está em constante metamorfose, diante dos desafios que se apresentam. Essa dinâmica nem sempre pode ser explicada pela razão, aliás, quase nunca o pode. Uma das características típicas de nossos tempos é a de colocar a tecnologia como a única forma possível de explicar o progresso da humanidade.

A tese da tecnocracia foi desenvolvida no plano científico em diferentes versões. 0 que parece mais importante é o seu poder de penetrar, enquanto ideologia de fundo, na consciência da massa despolitizada da população, e de gerar força legitimadora. Nessa perspectiva, subtrai a autocompreensão da sociedade, tanto do sistema de 
referência do agir comunicativo, como dos conceitos de interação simbolicamente mediatizados, substituindo-os por um modelo científico.

Ao longo da história da humanidade, a ciência busca afirmação através de avanços e recuos, especialmente no que se refere á valorizacão da formação humanavinculadaestreitamenteàrealização pessoal, às emoções, percepções e sensibilidades. Avançou-se muito na metodologia que possibilita ver o mundo externo, lá fora. Mas é necessário voltar 0 olhar para uma ciência que permita 0 acesso ao mundo interno, de dentro, conectado intimamente com 0 externo. Isso possibilita compreender 0 funcionamento intelectual, a consciência e o processo de construção do conhecimento. No entanto, não se pode penetrar neste mundo interior sem subverter tudo o que se sabe sobre o mundo exterior. 0 ser humano é parte da realidade observada e, como no esquema de Moebius modifica a realidade externa na medida em que se modifica a si mesmo. Essa visão assinala para a importância da criatividade. A palavra possibilita 0 acesso aos significados das emoções e realizações humanas. Autoorganização, reconstrução, linguagem são fios que tecem a realidade. Realidade incerta, encantada, a ser construída pelos sujeitos, atores e construtores de suas vidas. Nada é já dado. Tudo está aí para ser construído, em cada momento da vida. Essa lógica admite a transversalidade do conhecimento e da essência. A incerteza é uma constante, mas substitui em parte, a lógica racional.Aliar a formação humana à qualificação, à formação continuada que engloba a tecnologia e os saberes já construídos significa um passo além, mas ainda constitui-se em um desafio. Diferentes olhares humanos, olharespoéticos, olhares dramáticos, olhares na sombra, olhares subversivos, olhares afetivos, olhares suspeitosos, olhares científicos certamente poderão auxiliar a perceber melhor essa trama complexaexistenteno mundo atual, aliando tecnologia com humanização nas ciências, nas artes , no processo de construção e de produção do conhecimento.

A trajetória profissional, referindo os professores de diversas áreas do conhecimento insere-se nessa teia onde a tecnologia tende a asfixiar o humano. É típica de nossos tempos. Mas, quase sempre há espaço para as contradições, eénecessário vincular discernimento e vontade com autorrealização, bem estar, diálogo e interação social. Falar sobre o mundo é criá-lo, ou melhor, recriá-lo, e esse convite é desafiador. Lembra-se a profunda reflexão de Viñar (1993, p. 18): "Enquanto dialogamos, o cosmos altera a idéia de si próprio."
Vínculos iniciais da vida asseguram uma base segura para lidar com o cotidiano, fazer escolhas, inclusive no âmbito profissional. Trajetórias de vida e trajetórias profissionais inserem-se na gama de projetos humanos, que possibilita sentido á existência. Identificações com figuras de vínculo também permeiam motivações para as escolhas profissionais e, nesse âmbito, 0 imaginário desempenha um importante papel, associando sonhos, projetos, vivências, desejos com a realidade, com as escolhas do cotidiano. Significa conhecer a familiaridade das ações e de sua prática, ações essas que vão dando forma à construção do real. As imagens formadoras se atualizam em suas inserções no dia-a-dia de cada um. 0 confronto com as vicissitudes da vida exige a elaboração do sofrimento gerado pela falta, pelas perdas, que podem ser diversas: desde a mudança de cidade, até aperdapormortedeuma pessoaamada. 0 confronto com a dor, sem qualquer negação, favorece a elaboração. A partir daí é possível ressignificar práticas profissionais criativas e os elos com a existência. Ao longo do ciclo de vida, seres humanos sofrem impactos do interjogo existente entre identificação e desidentificação.

Muitas vezes, instaura-se certo distanciamento que, depois de elaborado, passa a ser devolvido pelo próprio sujeito a si mesmo Momentos atuais são também momentos de incerteza e, por si mesmos representam desafios importantes, que podem levar a fraturas na identidade e nos processos de identificação. Um tempo nem grandioso, nem épico, antes prosaico, porém fecundo. Voltando o olhar para o professor, pode-se referir que existe um fio condutor em sua identidade e trajetória, permeada por múltiplas imagens, percepções e sensibilidades, que estão envoltos nas tramas da memória e da história de cadaum. Muitas vezes, as vicissitudes seapresentam como momentos de incerteza, de fragmentação desse fio condutor que articula identidade, memória e projeto de vida. Podem quebrar-se imagens de si, estruturas subjetivas, e o professor podepermanecer preso a uma formação anterior, que já não coincide sequer com suas expectativas pessoais. Crises aparecem, até mesmo pelas mudanças aceleradas, que reclamam por um olhar mais atento às manifestações da memória diante das vicissitudes da vida. As crises vitais e as tramas sociais representam registros diacrônicos na história de vidadas pessoas. D iantedessas questões, aformação 
reveste-se de importância, ressignificando 0 caminho, a realidade e a própria vida, permeada por escolhas e confrontos permanentes.

Uma dissociação entre formação profissional e humana cinde o sujeito de seu próprio tempo efragmentao conhecimento. Tanto aformação permanente, a formação profissional, quanto a formação humana passam por continuidades e rupturas, mas integram, configuram e reconfiguram projetos de vida. E necessário voltar o olhar para a formação do professor que, em muitos casos, não coincide com as demandas atuais. Encontrar os vínculos entre tempo e ensinar, tempo e aprender resulta familiar aos coletivos docentes Encontrar os mesmos vínculos entre tempo e formação do ser humano resulta distante. A dificuldade está na falta de familiaridade com a formação. Será, então, que a formação é estranha à docência? Por que será, se educação e formação sempre caminharam tão próximas? Sabe-se bastante sobre o que, e sobre como ensinar, mas sabe-se pouco sobre a formação humana: professores e alunos como sujeitos totais, éticos, culturais, estéticos, afetivos. 0 movimento de realização permite 0 aparecimento de fenômenos educativos, no sentido estrito do termo, que os vincula aos significados. 0 fundamento dos fenômenos e seus desdobramentos se manifestam numa temporalidade, numa especialidade, existencialmente, e não apenas como resultado de recursos metodológicos. A essência daquilo que existe está no como este isto se manifesta, e existe coincidência entre o ser, o isto, a aparência, a manifestação da realidade. Estes aspectos estão implícitos também no processo de atribuição de significados às vivências e experiências. É um movimento dinâmico, como a própria vida.

\section{CON SIDERAÇÕES FIN AIS}

A formação humana não é linear, e isso parece ser de domínio comum. Em algum momento da existência, cada ser humano convive com algum tipo de sofrimento, que é mais ou menos intenso para cada um. Períodos de transição do ciclo de vida são permeados pelas incertezas e por desafios constantes. Simultaneamente, a sociedade exige pessoas solidárias, pacientes etolerantes. 0 exercício profissional também requerinvestimentos contínuos para acompanhar o ritmo intenso do progresso e 0 modo apressado de vida que caracteriza a contem- poraneidade. Nossos estudos, bem como os resultados de pesquisas realizadas com professores assinalam para algumas questões importantes, presentes no cotidiano dos participantes, ao identificar significados que reportam este professor ao início da vida e ao convívio com figuras primitivas, com um modelo de formação que já não condiz com nossos dias. Muitas vezes, essas questões dificultam o processo de adesão a programas de capacitação, interferem na relação professor-aluno, na qualidade do ensino e na autorrealização.

A literatura existente sobre formação de professores inclui referências a técnicas, domínios didático-pedagógicos, mas esquece o professor como ser humano. Alguns autores referem-se às questões de sensibilidade, de experiências sensíveis. Outros, entretanto contestam essas necessidades. 0 trabalho deve vincular-se ao prazer, especialmente para 0 professor que lida diretamente com a formação de pessoas e com 0 ensino. Se estiver insatisfeito, 0 reflexo sobre o ensino é direto. $\mathrm{Na}$ área das Artes Visuais, o conhecimento vincula-se a questões de sensibilidade, ao imaginário e, diante das contradições, muitas vezes a criatividade sofre certa estagnação. Nestaárea, particularmente o exercício da criatividade, dos processos criativos associa-se a um domínio essencial. Essas reflexões assinalam para a formação humana, para a formação permanente de professores, também naárea das Artes Visuais. 0 desenvolvimento do ser humano permite que se alterem significados de imagens formadoras vinculadas a modelos primitivos deidentificação. Trata-se de um movimento dinâmico, que se insere na história de cada um e que interfere em suas interações com 0 outro, com os alunos, com 0 objeto de estudo desuaformação, configurando novas representações mentais. Essas representações mentais configuram- se e reconfiguram-se continuamente, coerentes com a dinâmica da vida. 0 imaginário cumpre um papel de relevância na constituição das representações mentais, assegurando a marca pessoal, peculiar a cada uma delas, inserida na vida de cada um.

Atividades de ensino em Artes Visuais podem favorecer a compreensão de estratégias, bem como a interpretação de objetos físicos e midiáticos que constituem a cultura visual. 0 professor de Artes Visuais necessita assim, de diferentes domínios, do exercício da função criativa e da capacidade imaginativa. A produção artística insere-se na trama conceitual proposta por Vygotsky, uma vez que a imaginação, a atribuição de significados, processos indispensáveis para a construção de sentidos não 
pode ser descontextualizada, e requer o exercício dessas funções, que estão implícitas também, no processo de aquisição do conhecimento. Trata-se de uma complexa trama conceitual envolvida nos significados, no processo de construção do conhecimento e nas experiências do ato de criação. Fluxo contínuo de ser o tempo e estar no espaço: presença de vida.

As afinidades proporcionadas pela intimidade com 0 instrumental teórico-conceitual fornecido pelas leituras realizadas, que integraram diferentes áreas do conhecimento, tais como Psicologia, Educação, Arte, dentre outras oportunizaram a realização de análises, que remetem tanto às reflexões sobre a formação humana, quanto à necessidade de atualização contínua sobre novos domínios. A formação permanente de professores de diferentes áreas do conhecimento possui um sentido de torná-losleitores críticos desuas próprias histórias, memórias etrajetórias, capazes de reescrevereatribuir sentido histórico ao conhecimento.

\section{REFERÊNCIAS}

Bakhtin, M. (1976). Freudianism: A marxist critique. New York: Academic Press.

Benjamin, W. (1987). Magia-técnica, arte e política. São Paulo: Brasiliense. (O bras Escolhidas).

Enguita, M. (1989). A face oculta da escola. Porto Alegre: Artes Médicas.

Meltzer, E. E. (1989). Identity: Youth and crisis. New York: Norton Press.

Freitas, N. K. (2005). El trabajo de creación las crísis: Significaciones. Revista Alternativas en Psicología, 10(11), 50-55.

Luria, R. (1992). Mente e memória. São Paulo: Martins Fontes.

Meltzer, D. (1988). The aprehension of beauty. $G$ reath Britain: Harris Library.

Pasolini, P. (1990). Os jovens infelizes. São Paulo: Brasiliense.

Passeron, R. (1997). Elodge del ombre. Paris: Minuit.
Rego, C. L. (2002). Vygotsky: Uma perspectiva histórico-cultural da educação. Petrópolis: Vozes.

Vasconcellos, M. (2002). Criatividade. São Paulo: Moderna.

Viñar, R. (1993). Identificación. Barcelona: Nueva Visión.

Vygotsky, L. S. (1984). Psicologia pedagógica. São Paulo: Martins Fontes.

Vygotsky, L. S. (1986). La imaginación y el arte en la infancia. Madrid: Akal.

Vygotsky, L. S. (1987). A formação social da mente. São Paulo: Martins Fontes.

Vygotsky, L. S. (2001). A psicologia da arte. São Paulo: Martins Fontes.

Wallon, H. (1979). Objectivos y metodos de la psicología. Portugal: Estampa.

Recebido: 20/ 08/ 2008

Received: 08/ 20/ 2008

Aprovado: $20 / 11 / 2008$

A pproved: $11 / 20 / 2008$ 